\title{
ARE THERE DIFFERENCES IN STRENGTH TESTS USING ISOKINETIC DYNAMOMETRY BETWEEN FIELD AND INDOOR PROFESSIONAL SOCCER PLAYERS?
}

Adriano Barros de Aguiar Leonardi ${ }^{1}$, Mauro Olivio Martinelli ${ }^{2}$, Aires Duarte Junior ${ }^{3}$

\section{ABSTRACT}

Objective: The objective of this study was to conduct a comparative analysis on isokinetic strength assessments between field and indoor male professional soccer players and correlate the findings with the higher levels of injury risk described in the literature. Methods: We analyzed 16 field soccer players and 15 indoor soccer players. All these professionals were male. Isokinetic muscle strength assessments were made on their knees. Results: The mean weight was $81.81 \mathrm{~kg}$ for field soccer and $80.33 \mathrm{~kg}$ for indoor soccer. The right and left peak extensor torque left and right for field soccer and indoor soccer were, respectively, 302.50 and $313.31 \mathrm{Nm}$ and 265.20 and $279.80 \mathrm{Nm}$, and for flexors, 178 and $184.88 \mathrm{Nm}$ and 158.27 and $154 \mathrm{Nm}$. The peak torque rates according to body weight for the left and right extensors for field soccer and indoor soccer were, respectively, 3.84 and $3.7 \mathrm{Nm} / \mathrm{kg}$ and 3.32 and $3.52 \mathrm{Nm} / \mathrm{kg}$, and for flexors, 2.17 and 2.26 $\mathrm{Nm} / \mathrm{kg}$ and 1.98 and $1.93 \mathrm{Nm} / \mathrm{kg}$. The balance relationships between flexors and extensors on the right and left sides for field soccer and indoor soccer were, respectively, 59.81 and $59.44 \%$ and $60.47 \%$ and $54.80 \%$. The relationships for extensors between the right and left sides for field soccer and indoor soccer were, respectively, 11.44 and $9.20 \%$, and for the flexors, 7.31 and $8.80 \%$. Conclusions: In accordance with international parameters, comparative analysis on isokinetic strength assessments between field and indoor male professional soccer players before the season showed that there was muscle balance and low probability of injury. There were no statistically significant differences in the parameters analyzed between the players of the two types of soccer.

Keywords - Isometric Contraction; Soccer; Muscle Strength Dynamometer

\section{INTRODUCTION}

Indoor soccer and field soccer are both very popular forms of sports activity and are correlated with high injury rates, accounting for 50 to $60 \%$ of all sports injuries, which leads to a high rate of time off games and training among the players $^{(1)}$. This may result in economic losses both for players and for clubs. Studies worldwide have reported that the annual expenditure on professional soccer players who are off the game because of sports injuries is around 20 million dollars ${ }^{(2,3)}$. Other studies have also reported high recurrence rates for soccer injuries, thus resulting in longer periods off the game and even greater declines in performance ${ }^{(1,4)}$. Knowledge of the main risk factors associated with these injuries would make it possible to develop preventive interventions, thereby diminishing the number of injuries and their negative consequences for the clubs and for the players ${ }^{(4-6)}$.

Isokinetic evaluation has been used over the last three decades as a method for determining the functional pattern of strength and muscle balance. Although the term isokinetic was defined in $1967^{(7)}$, isokinetic evaluations have only become more widespread over the last three decades. They have come into use

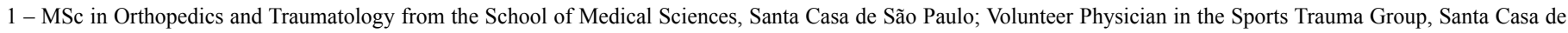
São Paulo, São Paulo, SP, Brazil.

2 - Volunteer Physician in the Sports Trauma Group, Santa Casa de São Paulo, São Paulo, SP, Brazil.

3 - Head of the Sports Trauma Group, Department of Orthopedics and Traumatology, School of Medical Sciences, Santa Casa de São Paulo, São Paulo, SP, Brazil.

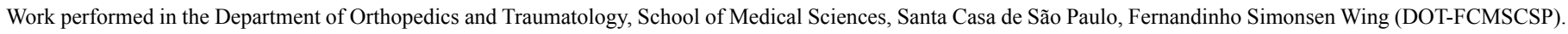
Director: Prof. Dr. Osmar Avanzi

Correspondence: Rua Mantiqueira 230, ap. 84, Vila Mariana, 04110-040 São Paulo, SP. E-mail: leonardi.adriano@uol.com.br

Work received for publication: February 12, 2011; accepted for publication: August 15, 2011.

The authors declare that there was no conflict of interest in conducting this work 
among Brazilian sports clubs as a tool for injury prevention, implemented during the preseason period ${ }^{(8,9)}$.

The indications for the examination relate to studying the proportions of agonist and antagonist muscle balance and the difference in agonist muscle groups between one side and the other. The results are grouped in terms of the following: peak torque, analyzing the point of highest torque within the range of movement; work, representing the energy output through muscle effort during movement, expressed in joules (J); power, the result from work achieved divided by time, expressed in watts $(\mathrm{W})$; resistance, obtained when the number of repetitions is greater than or equal to six, representing the energy that uses anaerobic metabolism; and the agonist/antagonist balance relationship, i.e. the division between the agonist and antagonist values, in relation to the peak torque, work or power, expressed as a percentage ${ }^{(7,8)}$.

The agonist/antagonist ratio is an appropriate means for determining whether muscles are in proportion and consequently in balance. In the literature, the reported relationship of flexors to extensors in knees without injury usually ranges from $55 \%$ to $77 \%{ }^{(10,11)}$. The main abnormalities that have been indicated to be risk factors for soccer injuries are asymmetries in the muscle performance parameters between the dominant and nondominant limbs and modifications to the torque ratio between antagonist muscles ${ }^{(1,5,12)}$.

The aim of the present study was to conduct a comparative analysis on the results from isokinetic strength assessments among field and indoor male professional soccer players.

\section{SAMPLE AND METHODS}

\section{Sample analysis}

In this study, 16 field soccer players and 15 indoor soccer players (who were all professionals and all male) underwent isokinetic assessment of knee muscle strength. This type of evaluation has been used as a method for determining the functional pattern of muscle strength and balance and for assisting in rehabilitation of sports injuries ${ }^{(9)}$. During the isokinetic evaluation, certain parameters were measured.

\section{Description of the variables}

We analyzed the following parameters:

- PKT EXT R: peak torque of the right extensor muscle;

- PKT EXT L: peak torque of the left extensor muscle;
- PKT FLEX R: peak torque of the right flexor muscle; - PKT FLEX L: peak torque of the left flexor muscle; - PT/PC EXT R: ratio between peak torque of the right extensor muscle and the player's weight;

- PT/PC EXT L: ratio between peak torque of the left extensor muscle and the player's weight;

- PT/PC FLEX R: ratio between peak torque of the right flexor muscle and the player's weight;

- PT/PC FLEX L: ratio between peak torque of the left flexor muscle and the player's weight;

- F/E R: ratio between the peak torques of the right flexor and extensor muscles;

- F/E L: ratio between the peak torques of the left flexor and extensor muscles;

- R/L FLEX positive: measurement of flexor muscle imbalance; and

- R/L EXT positive: measurement of extensor muscle imbalance.

\section{Descriptive analysis}

The isokinetic evaluation parameters were summarized by means of summary measurement tables (means and standard deviations, for example) and boxplot graphs.

\section{RESULTS}

Figure 1 and Table 1 present the PKT measured among the field soccer players. We noted that the peak torque of the extensor muscle group was higher than that of the flexor muscle group. On the other hand, the measurements on the two knees did not differ much, for both muscles. The left knee presented higher peak torque, on average, for both muscles.

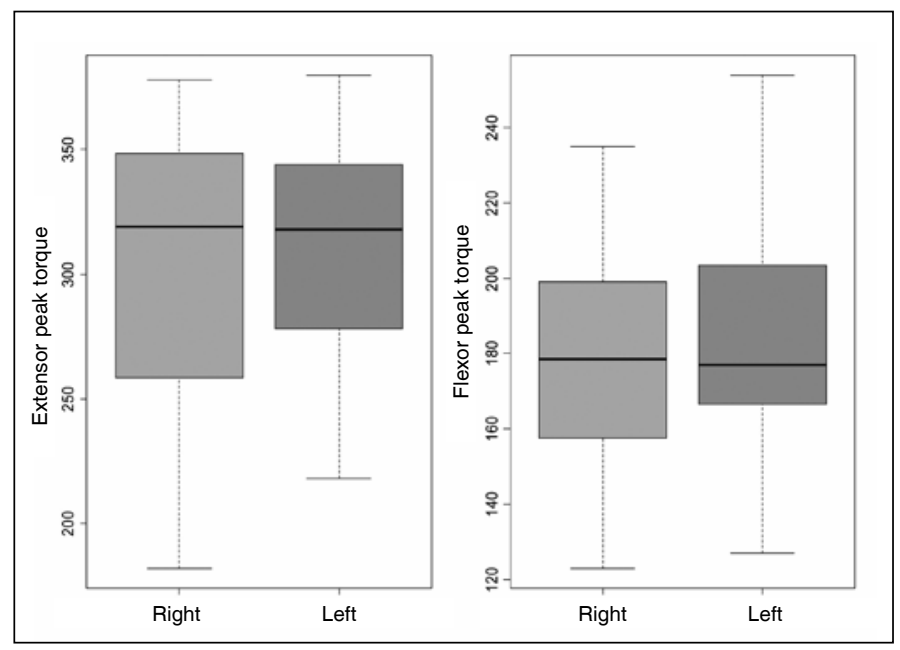

Figure 1 - Boxplot of peak torque for field soccer players. 
Table 1 - Summary measurements of peak torque for the field soccer players. Measurements in Newtons per meter (N/m).

\begin{tabular}{|c|c|c|c|c|c|c|c|c|c|}
\hline & & Mean & $\begin{array}{l}\text { Standard } \\
\text { deviation }\end{array}$ & Minimum & $\begin{array}{c}\text { First } \\
\text { quartile }\end{array}$ & Median & $\begin{array}{c}\text { Third } \\
\text { quartile }\end{array}$ & Maximum & $\mathrm{n}$ \\
\hline \multirow{2}{*}{ Extensor } & Right & 302.50 & 57.26 & 182 & 260.25 & 319 & 347.75 & 378 & 16 \\
\hline & Left & 313.31 & 44.16 & 218 & 278.00 & 318 & 344.00 & 380 & 16 \\
\hline \multirow{2}{*}{ Flexor } & Right & 178.00 & 33.54 & 123 & 158.75 & 178.5 & 195.50 & 235 & 16 \\
\hline & Left & 184.88 & 35.33 & 127 & 168.25 & 177 & 196.75 & 254 & 16 \\
\hline
\end{tabular}

Figure 2 and Table 2 present the PKT measured among the indoor soccer players. The same that was said regarding the peak torque measured in the extensor and flexor muscle groups of the field soccer players can be said about the indoor soccer players. We also noted lower variability of measurements made on the extensor muscle group, compared with the variability of the measurements made on the flexor muscle, in both knees.

From analysis on Table 3 and Figure 3, it could be seen that the $\mathrm{PT} / \mathrm{PC}$ ratios measured on the extensor muscle group were greater than the $\mathrm{PT} / \mathrm{PC}$ ratios measured on the flexor muscles, for both types of soccer player. The measurements made on the field soccer players also presented greater variability.

Figure 4 and Table 4 present the proportions of the flexor extension balance, both for the left knee and for the right knee, for both types of soccer player. It

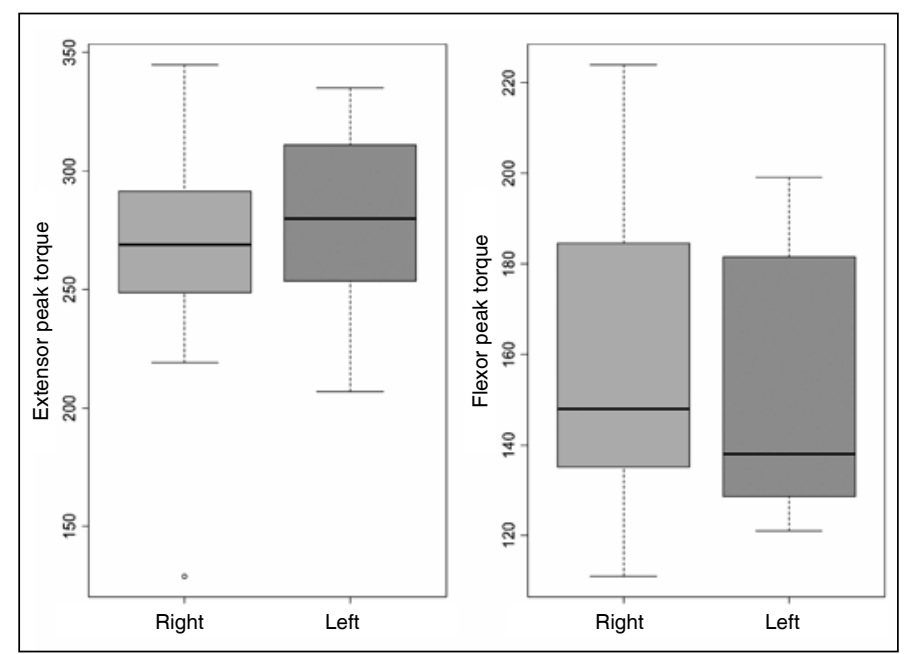

Figure 2 - Boxplot of peak torque for indoor soccer players. could be seen that the variability of the F/E measurements on the field soccer players was greater than the variability of the measurements made on the indoor soccer players, reaching twice as much in the left knee. Regarding the right knee, we noted the presence of discrepant points for both types of soccer player (90 and 86\% for field and indoors, respectively). On average, the indoor soccer players presented greater muscle balance $(60.47 \%)$.

Analysis on Figure 5 and Table 5 showed that there were discrepant $\mathrm{R} / \mathrm{L}$ values for both types of soccer player, in relation to the flexor muscle, and for the indoor soccer players in relation to the extensor muscle. For the extensor muscle, the R/L measurements were, on average, greater among the field soccer players. For the flexor muscle, the $\mathrm{R} / \mathrm{L}$ measurements were greater for the indoor soccer players. Because of the discrepant values, greater variability was observed in the measurements on the extensor muscles of the indoor soccer players.

\section{Inferential analysis}

With the aim of investigating whether the isokinetic evaluation parameters differed between the two types of soccer player, the nonparametric Mann-Whitney test was used, which compared the medians of pairs of independent samples. To compare the median values for muscle function (in our case, peak torque), between the left and right sides, the nonparametric Wilcoxon test for paired samples was used.

In comparing the absolute values for muscle function (in our case, peak torque), there were no significant differences between the left and right knees, for both muscles and both types of soccer player.

Table 2 - Summary measurements of peak torque for the indoor soccer players. Measurements in Newtons per meter (N/m).

\begin{tabular}{|c|c|c|c|c|c|c|c|c|c|}
\hline & & Mean & $\begin{array}{l}\text { Standard } \\
\text { deviation }\end{array}$ & Minimum & $\begin{array}{c}\text { First } \\
\text { quartile }\end{array}$ & Median & $\begin{array}{c}\text { Third } \\
\text { quartile }\end{array}$ & Maximum & $\mathrm{n}$ \\
\hline \multirow{2}{*}{ Extensor } & Right & 265.20 & 50.86 & 129 & 248.50 & 269 & 291.50 & 345 & 15 \\
\hline & Left & 279.80 & 39.18 & 207 & 253.50 & 280 & 311.00 & 335 & 15 \\
\hline \multirow{2}{*}{ Flexor } & Right & 158.27 & 33.16 & 111 & 135.00 & 148 & 184.50 & 224 & 15 \\
\hline & Left & 154.00 & 28.95 & 121 & 128.50 & 138 & 181.50 & 199 & 15 \\
\hline
\end{tabular}



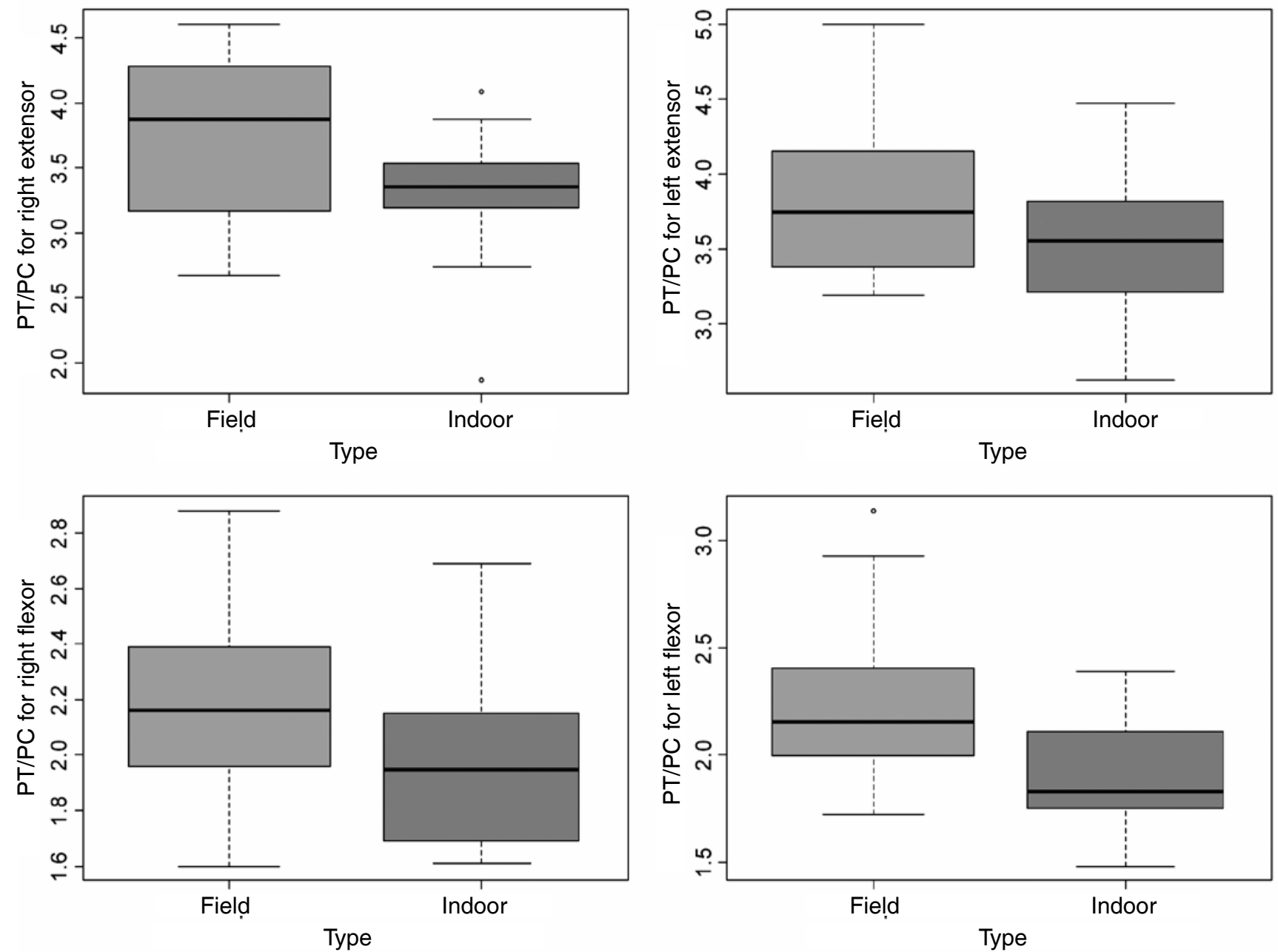

Figure 3 - Boxplot of PT/PC for both types of soccer players.

Table 3 - Summary measurements of PT/PC for both types of soccer. Measurements in Newtons per kilogram (Nm/kg).

\begin{tabular}{|c|c|c|c|c|c|c|c|c|c|}
\hline & & Mean & $\begin{array}{l}\text { Standard } \\
\text { deviation }\end{array}$ & Minimum & $\begin{array}{c}\text { First } \\
\text { quartile }\end{array}$ & Median & $\begin{array}{c}\text { Third } \\
\text { quartile }\end{array}$ & Maximum & $\mathbf{n}$ \\
\hline \multirow{2}{*}{$\begin{array}{c}\text { Right } \\
\text { extensor }\end{array}$} & Field & 3.70 & 0.68 & 2.67 & 3.24 & 3.88 & 4.26 & 4.61 & 16 \\
\hline & Indoor & 3.32 & 0.53 & 1.87 & 3.19 & 3.36 & 3.54 & 4.09 & 15 \\
\hline \multirow{2}{*}{$\begin{array}{c}\text { Left } \\
\text { extensor }\end{array}$} & Field & 3.84 & 0.56 & 3.19 & 3.42 & 3.745 & 4.00 & 5 & 16 \\
\hline & Indoor & 3.52 & 0.47 & 2.63 & 3.22 & 3.56 & 3.82 & 4.47 & 15 \\
\hline \multirow{2}{*}{ Right flexor } & Field & 2.17 & 0.35 & 1.6 & 1.99 & 2.16 & 2.39 & 2.88 & 16 \\
\hline & Indoor & 1.98 & 0.32 & 1.61 & 1.69 & 1.95 & 2.15 & 2.69 & 15 \\
\hline \multirow{2}{*}{ Left flexor } & Field & 2.26 & 0.40 & 1.72 & 2.00 & 2.155 & 2.39 & 3.14 & 16 \\
\hline & Indoor & 1.93 & 0.25 & 1.48 & 1.75 & 1.83 & 2.11 & 2.39 & 15 \\
\hline
\end{tabular}




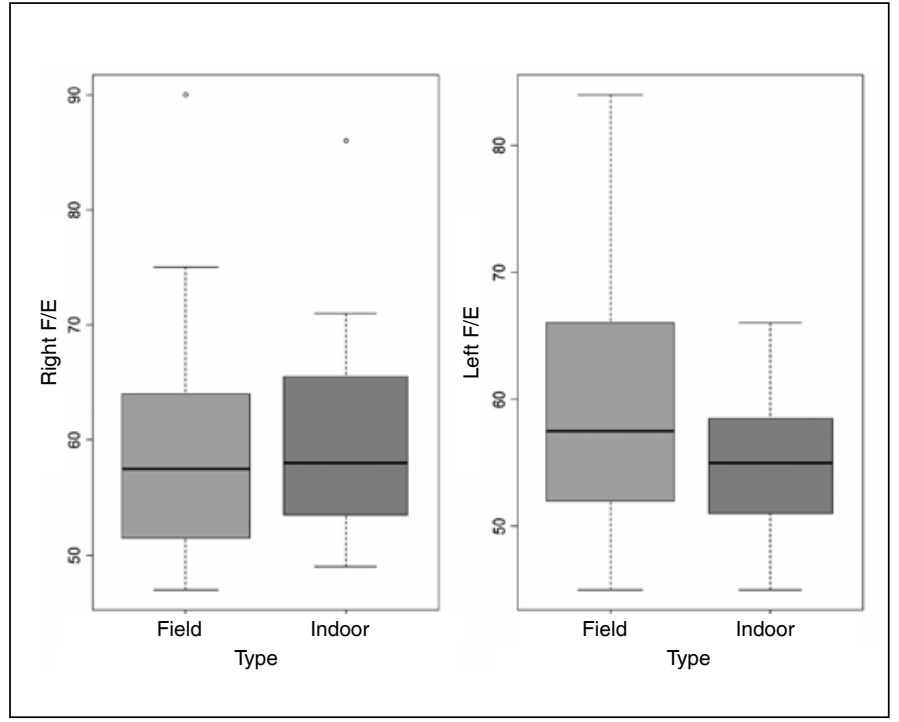

Figure 4 - Boxplot of F/E for both types of soccer players.

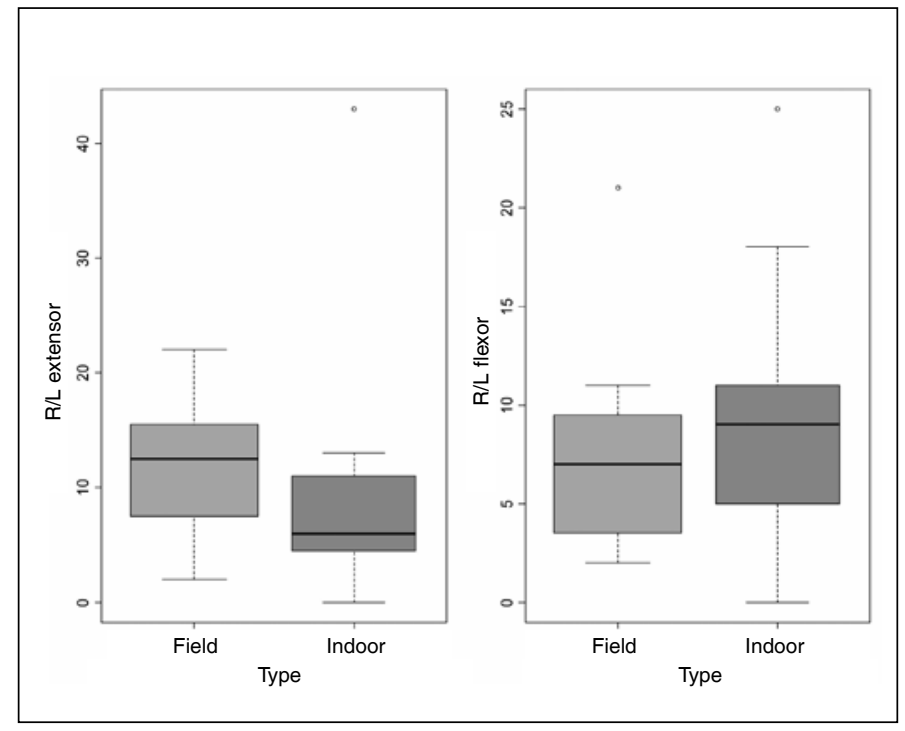

Figure 5 - Boxplot of R/L for both types of soccer players.

Table 4 - Summary measurements of F/E for both types of soccer. Measurements in percentages (\%).

\begin{tabular}{|c|c|c|c|c|c|c|c|c|c|}
\hline & & Mean & $\begin{array}{l}\text { Standard } \\
\text { deviation }\end{array}$ & Minimum & $\begin{array}{c}\text { First } \\
\text { quartile }\end{array}$ & Median & $\begin{array}{c}\text { Third } \\
\text { quartile }\end{array}$ & Maximum & $\mathrm{n}$ \\
\hline \multirow{2}{*}{ Right F/E } & Field & 59.81 & 11.23 & 47 & 51.75 & 57.5 & 63.00 & 90 & 16 \\
\hline & Indoor & 60.47 & 9.72 & 49 & 53.50 & 58 & 65.50 & 86 & 15 \\
\hline \multirow{2}{*}{ Left F/E } & Field & 59.44 & 10.76 & 45 & 52.00 & 57.5 & 64.50 & 84 & 16 \\
\hline & Indoor & 54.80 & 5.48 & 45 & 51.00 & 55 & 58.50 & 66 & 15 \\
\hline
\end{tabular}

Table 5 - Summary measurements of L/R for both types of soccer. Measurements in percentages (\%).

\begin{tabular}{c|c|c|c|c|c|c|c|c|c}
\hline & & Mean & $\begin{array}{c}\text { Standard } \\
\text { deviation }\end{array}$ & Minimum & $\begin{array}{c}\text { First } \\
\text { quartile }\end{array}$ & Median & $\begin{array}{c}\text { Third } \\
\text { quartile }\end{array}$ & Maximum & $\mathbf{n}$ \\
\hline $\begin{array}{c}\text { R/L } \\
\text { extensor }\end{array}$ & Field & 11.44 & 5.60 & 2 & 7.75 & 12.5 & 15.25 & 22 & 16 \\
\cline { 2 - 11 } & Indoor & 9.20 & 10.30 & 0 & 4.50 & 6 & 11.00 & 43 & 15 \\
\hline \multirow{2}{*}{ R/L flexor } & Field & 7.31 & 4.64 & 2 & 3.75 & 7 & 9.25 & 21 & 16 \\
\cline { 2 - 11 } & Indoor & 8.80 & 6.43 & 0 & 5.00 & 9 & 11.00 & 25 \\
\hline
\end{tabular}

To evaluate differences in peak torque, the parameter PT/PC (peak torque in relation to the player's weight) was used. We could affirm that there was a significant difference in PT/PC FLEX L between the two types of soccer player $(\mathrm{p}=0.013$; median difference $=0.27$ with $95 \% \mathrm{CI}=[0.08 ; 0.52])$.

In relation to the proportions of flexor/extensor muscle balance $(\mathrm{F} / \mathrm{E})$, there were no significant differences, either for the right knee or for the left knee. The same was seen in analyzing the parameter $\mathrm{R} / \mathrm{L}$ between the types of soccer player.

\section{DISCUSSION}

Both field soccer and indoor soccer (known as "futsal" in Brazil), which are sports with similar movements, have gone through a process of improvement of the technical level over recent years. Biomechanical studies, together with greater comprehension of the physiology of the sport have optimized the players' yield. Field soccer has gained prominence and popularity, and now produces high-performance players rather than the "shooters" of the start of the century. 
The aim of this study was to conduct a comparative analysis on the results from isokinetic assessment among field and indoor male professional soccer players. The isokinetic apparatus used was a dynamometer in which individuals made maximal or submaximal muscle exertion that was accommodated by the resistance of the apparatus. Since these evaluations relate to injury prevention, most clubs have started to use them during the preseason period ${ }^{(13)}$.

There are several studies worldwide that have characterized soccer players' muscle performance, especially in relation to the maximum capacity to produce muscle torque ${ }^{(14,15)}$. In comparison with the soccer players assessed in those studies, the Brazilian players presented better muscle performance in relation to flexion and extension movements in the knee joint ${ }^{(15,16)}$. We believe that this was due to methodological differences such as the type of dynamometer used and/or the players' positioning during the evaluation. Another possible explanation could be the specific features of training on and off the field (muscle building) that might exist between different countries or between different soccer clubs.

The preventive parameters that we analyzed were the coefficients of peak torque in relation to weight (PKT/PC), peak torque of extensors and flexors and the coefficient between these. As also described in results in the literature, we found mean values that were greater than in the general population $^{(3)}$. This difference in the players' muscle performance is possibly related to the high physical demands imposed by professional soccer practice. In this case, not only the sport itself but also the training needed to prepare players, like training sessions on the field or muscle-building may explain the better muscle performance among players than in the general population.

However, we did not find any studies in the literature comparing the results from strength analysis for the two types of soccer player. In analyzing the peak torque of the flexor and extensor muscles of the right and left sides, we noted that the peak torque of the extensor muscles was higher than that of the flexor muscles. The measurements made on the two knees did not differ much for either of the muscles. We attribute this to the need for kicking strength, which is common to both types of soccer (Table 1 and Figure 1). We attribute the greater variability found in field soccer to the differentiated training between players in different positions, such that endurance training is directed towards the wingers, midfield defenders and midfielders, while muscle explosion training is directed towards goalkeepers and strikers. These differences are more accentuated in field soccer, because of the longer distances that the players have to cover. We believe that this is also related to the lower variability in the measurements made on the extensor muscle than in measurements on the flexor muscle, in both knees (Table 2 and Figure 2).

We noted greater variability in the PT/PC values of the extensor and flexor muscles, for both types of soccer. We attribute this too to the differentiated training between the players' positions. We also believe that this is connected with our observation that the variability of $\mathrm{F} / \mathrm{E}$ measurements among field soccer players was greater than the variability of the measurements made among the indoor soccer players.

In the literature, special attention is given to interpreting the results from the relationship between agonist and antagonist muscles. It is accepted that the value of an uninjured muscle group can be considered to be normal, provided that it is the same as, or not more than $10 \%$ different from the contralateral muscle group $^{(9)}$. For performing sports activities, differences of up to $20 \%$ may be accepted. Values for this ratio lower than $60 \%$ have been associated with distension of the hamstrings ${ }^{(5,16)}$.

In the present study, the values observed in the two types of soccer were homogenous, since there was minimal variation in the coefficients of flexion/extension between the right and left sides among the sample studied (Figure 4 and Table 4). However, our results are inferior to those presented in studies worldwide ${ }^{(9)}$. Although the players without histories of injuries that we assessed presented values for this ratio of 54.60 to $60.47 \%$ in indoor soccer and 59.44 to $59.81 \%$ in field soccer, we believe that these findings indicate that these players had agonist/antagonist ratios that were adequate for sports practice.

We also noted that the variability in the F/E measurements among the field soccer players was greater than the variability of the measurements on the indoor soccer players, and that they were twice the magnitude in the left knee. On average, indoor soccer players presented greater muscle balance (60.47\%). Again, we attribute this to the differentiated training between players in different positions; to the more homogenous training among indoor soccer players, in relation to field soccer players; and to the predominance of right-handed players. 


\section{CONCLUSIONS}

In accordance with international parameters, this comparative analysis on the results from isokinetic strength assessments among field and indoor male professional soccer players showed that muscle balance existed.

There were no statistically significant differences in the parameters analyzed between the players of the two types of soccer.

\section{REFERENCES}

1. Keller CS, Noyes FR, Buncher CR. The medical aspects of soccer injury epidemiology. Am J Sports Med. 1987;15(3):230-7.

2. Knapik JJ, Bauman CL, Jones BH, Harris JM, Vaughan L. Preseason strength and flexibility imbalances associated with athletic injuries in female collegiate athletes. Am J Sports Med. 1991;19(1):76-81.

3. Lentell G, Katzman LL, Walters MR. The Relationship between Muscle Function and Ankle Stability. J Orthop Sports Phys Ther. 1990;11(12):605-11.

4. Taylor DC, Dalton JD Jr, Seaber AV, Garrett WE Jr. Experimental muscle strain injury. Early functional and structural deficits and the increased risk for reinjury. Am J Sports Med. 1993;21(2):190-4.

5. Ekstrand J, Gillquist J. The avoidability of soccer injuries. Int J Sports Med. 1983 May;4(2):124-8.

6. Aagaard P, Simonsen EB, Magnusson SP, Larsson B, Dyhre-Poulsen P. A new concept for isokinetic hamstring: quadriceps muscle strength ratio. Am J Sports Med. 1998;26(2):231-7.

7. Hislop HJ, Perrine JJ. The isokinetic concept of exercise. Phys Ther. 1967;47(2):114-7.

8. Greve JM, Terreri AS, Plapler PG. [Evaluation of isokinetic trunk flexion and extension in normal sportsman and sedentary people]. Rev Hosp Clin Fac Med Sao Paulo. 1997;52(3):154-8.

9. Terreri AS, Ambrósio MA, Pedrinelli A, Albuquerque RF, Andrusaitis F, Greve $\mathrm{JM}$, et al. Isokinetic assessment of the flexor-extensor balance of the knee in athletes with total rupture of the anterior cruciate ligament. Rev Hosp Clin Fac Med Sao Paulo. 1999;54(2):35-8.

10. Grace TG, Sweetser ER, Nelson MA, Ydens LR, Skipper BJ. Isokinetic muscle imbalance and knee-joint injuries. A prospective blind study. J Bone Joint Surg Am. 1984;66(5):734-40.

11. Harilainen A, Alaranta $H$, Sandelin J, Vanhanen I. Good muscle performance does not compensate instability symptoms in chronic anterior cruciate ligament deficiency. Knee Surg Sports Traumatol Arthrosc. 1995;3(3):135-7.

12. Heidt RS Jr, Sweeterman LM, Carlonas RL, Traub JA, Tekulve FX. Avoidance of soccer injuries with preseason conditioning. Am J Sports Med. 200;28(5):659-62.

13. Fonseca ST, Ocarino JM, Silva PLP, Bricio RS, Costa CA, Wanner LL. Caracterização da performance muscular em atletas profissionais de futebol. Rev Bras Med Esporte. 200713 (3): 143-7.

14. Alonso AC, Greve JMD, Macedo OG, Pereira CAM, Souza DCM. Avaliação isocinética dos inversores e eversores de tornozelo: Estudo comparativo entre atletas de futebol e sedentários normais. Rev Bras Fisiot. 2003;7(3):195-9.

15. Zakas A, Mandroukas K, Vamvakoudis E, Christoulas K, Aggelopoulou N. Peak torque of quadriceps and hamstring muscles in basketball and soccer players of different divisions. J Sports Med Phys Fitness. 1995;35(3):199-205.

16. Perrin DH, Robertson RJ, Ray RL. Bilateral isokinetic peak torque, torque acceleration energy, power, and work relationships in athletes and nonathletes. J Orthop Sports Phys Ther. 1987;9(5):184-9. 